\title{
The Factors on Removal of Zinc Cation from Aqueous Solution by Bentonite
}

\author{
Shuli Ding', Juanjuan Shen ${ }^{1}$, Bohui Xu' ${ }^{1}$, Qinfu Liu', Yuzhuang Sun ${ }^{1}$ \\ ${ }^{1}$ Key Laboratory of Resources Reconnaissance of Hebei Province, Hebei University of Engineering, Handan, China; ${ }^{2}$ School of \\ Resources and Safety Engineering, China University of Mining \& Technology, Beijing, China. \\ E-mail: dingshuli1@126.com
}

Received January 29 $9^{\text {th }}, 2011$; revised March $7^{\text {th }}, 2011$; accepted March $15^{\text {th }}, 2011$.

\begin{abstract}
The removing zinc cation from aqueous solution by Ca-bentonite and Na-exchanged bentonite was studied. The factors such as the initial concentration of $\mathrm{Zn}^{2+}$, the liquid-to-solid ratio, $p H$, adsorption time, stirring speed, coexisting ions, temperature and bentonite particle size were investigated. The results show that the adsorption process of bentonite accorded with the Freundlich isotherm model, the removal of $\mathrm{Zn}^{2+}$ by Ca-bentonite and Na-exchanged bentonite reached equilibrium in $2 \mathrm{~h}$, and adsorption of $\mathrm{Na}$ - bentonite was superior to Ca-bentonite. The adsorption rate of zinc increased with increasing $\mathrm{pH}$, temperature, stirring speed, time span and with decreasing bentonite particle, the initial concentration of $\mathrm{Zn}^{2+}$ and the liquid-to-solid ratio. In mixed solution which contains $\mathrm{Pb}^{2+}$ and $\mathrm{Cr}^{6+}, \mathrm{Pb}^{2+}$ has no influence on the removal of $\mathrm{Zn}^{2+}$ by both the bentonites while $\mathrm{Cr}^{6+}$ can decease it.
\end{abstract}

Keywords: Bentonite, $\mathrm{Zn}^{2+}$, Adsorption

\section{Introduction}

Heavy metals are typical and persistent environmental pollutants. Because of its toxicity and nonbiodegradable nature, metals are of special significance. The presence of heavy metals in wastewater and surface water is becoming a severe environmental and public health problem. Recently, natural materials, which are good sorbents and inexpensive have received much attention in heavy metal wastewater treatment [1-3]. Bentonite is the most abundant phyllosilicate mineral and its main mineral component is montmorillonite. Bentonite which was used in wastewater treatment has the advantage of simple device, low cost, no repollution etc.

The adsorption capacity of montmorillonite for heavy metal ions has been concerned since 1960s [4-8]. In literature various types of bentonite adsorbents have been cited. H. Omar et al. [9] investigated the adsorption potential of raw and formaldehyde modified-bentonite for the removal of ${ }^{60} \mathrm{Co}$ radionuclide from radioactive waste solutions. S. T. Akar et al. [10] combined white rot fungi and montmorillonite, this proposed was successfully used to sequester of copper ions from real wastewater in continuous mode. E. Alvarez-Ayuso et al. [11], concluded that both the Ca-montmorillonite and na-montmorillonite can remove heavy metals from the industrial effluent efficiently. W. Matthes et al [12]. studied sorption of $\mathrm{Al}$ and $\mathrm{Zr}$-hydroxy intercalated and pillared bentonite and found that the adsorption of heavy metal by montmorillonite was majorly due to the coordination of surface hydroxyl groups as well as the interchange with cation among crystal layers.

The major objective of this work is to study the adsorption of $\mathrm{Zn}^{2+}$ in aqueous solution as well as its influencing factors. Handan Ca-bentonite and Na-exchanged bentonite were used in the experiments with the view to discovering their metal ion recovery potential from effluents. The adsorption effect of $\mathrm{Cr}^{6+}$ and $\mathrm{Pb}^{2+}$ compete with $\mathrm{Zn}^{2+}$ in aqueous solution was analyzed.

\section{Materials and Methods}

\subsection{Equipment}

The X-ray diffraction (D/max-2200 diffractometer at a scanning speed $4^{\circ}(2 \theta) / \mathrm{min}$, using $\mathrm{CuK} \alpha$ radition at $40 \mathrm{kV}, 100 \mathrm{~mA}$ ) was used to identify the Mineral composition. 721 model spectro-photometer was used to measure the content of $\mathrm{Zn}^{2+}, \mathrm{Cr}^{6+}$ and $\mathrm{Pb}^{2+}$ in solutions. Also, the AW120 electron balance, HJ-5 constant temperature magnetic force beater, pHS-3C acidimeter, anion and cation exchange column, GL-20G- II model high-speed refrigerated centrifuge and some other instruments were 
used in experiments.

\subsection{Materials}

The Ca-bentonite M-1 was obtained from Handan district (Hebei Province, China). It was purified in the laboratory to remove carbonates, iron, hydroxide and organic matter. The bentonite was then crushed, ground, sieved through 200 mesh and dried at $105^{\circ} \mathrm{C}$ in an oven. Its mineralogical composition, chemical components and physicochemical properties are listed in Table 1 to $\mathbf{3}$ respectively.

All the other reagents used were of analytical grade and were obtained from Merck (Darmstadt, Germany). Metal salts of $\mathrm{ZnCl}_{2} \cdot 2 \mathrm{H}_{2} \mathrm{O}, \mathrm{Pb}\left(\mathrm{NO}_{3}\right)_{2}$, potassium dichromate $\left(\mathrm{K}_{2} \mathrm{Cr}_{2} \mathrm{O}_{7}\right)$ were used to prepare metal ion solutions. The solutions $(1000 \mathrm{~g} / \mathrm{L})$ were prepared by dissolving appropriate amounts of metal salts in doubly distilled water. The working solutions were prepared by diluting the stock solutions to appropriate volumes. $\mathrm{pH}$ adjustments of these solutions were made by $0.01,0.1$ and $1 \mathrm{M} \mathrm{HNO}_{3}$ and $\mathrm{NaOH}$ solutions.

\subsection{Preparation of Na-Bentonite}

The Na-exchanged bentonite M-2 was prepared as follows: the raw bentonite $\mathrm{M}-1$ was mixed up with $\mathrm{Na}_{2} \mathrm{CO}_{3}$ according to $100: 3$, the slurry was made with deionized

Table 1. Mineral composition of Ca-bentonite

\begin{tabular}{cc}
\hline Mineral & Percentage \\
\hline calcium montmorillonite & 61.7 \\
kaolinite & $0 \sim 6$ \\
illite & $2 \sim 8$ \\
feldspar & $2 \sim 11$ \\
quartz & $2 \sim 9$ \\
gypsum & $2 \sim 20$ \\
cristobalite & $1 \sim 8$ \\
\hline
\end{tabular}

Table 2. Chemical component of Ca-bentonite

\begin{tabular}{cc}
\hline Components & Percentage \\
\hline $\mathrm{SiO}_{2}$ & 61.10 \\
$\mathrm{Al}_{2} \mathrm{O}_{3}$ & 18.19 \\
$\mathrm{Fe}_{2} \mathrm{O}_{3}$ & 5.48 \\
$\mathrm{CaO}$ & 1.59 \\
$\mathrm{MgO}$ & 1.90 \\
$\mathrm{Na}_{2} \mathrm{O}$ & 1.30 \\
$\mathrm{~K}_{2} \mathrm{O}$ & 1.28 \\
$\mathrm{TiO}_{2}$ & 0.54 \\
LOI (loss on ignition) & 8.62 \\
\hline
\end{tabular}

Table 3. Physicochemical properties of Ca-bentonite

\begin{tabular}{cc}
\hline Properties & Value \\
\hline Cation exchange capacity $(\mathrm{mmol} / \mathrm{g})$ & 0.61 \\
Specific surface area $\left(\mathrm{m}^{2} / \mathrm{g}\right)$ & 20 \\
Colloid index $(\mathrm{mL} / \mathrm{g})$ & 4.13 \\
Epansion multiple $(\mathrm{mL} / \mathrm{g})$ & 9 \\
\hline
\end{tabular}

water in liquid-to-solid ratio of 10:1 afterwards. This suspension was stirred using the magnetic stirrer for $1 \mathrm{~h}$, then standing, removal of the underlying sandy, centrifuging, drying, grinding. The sample was subsequently referred to as Na-exchanged bentonite adsorbent.

\subsection{Method}

Adsorption on the samples was determined in batch sorption experiments in the single species system. Adsorption experiments were carried out by shaking a certain particle size of the bentonite with $100 \mathrm{~mL}$ of metal ions solution at a certain concentration in covered polyethylene containers. The $\mathrm{pH}$ of the solution was kept constant by the addition of $\mathrm{HNO}_{3}$ or $\mathrm{NaOH}$ solutions as needed. Subsequently, the suspension was stirred on the magnetic stirrer at controlled temperature and stirring rate. Standing for $2 \mathrm{~h}$ after equilibrium and then centrifuged for $10 \mathrm{~min}$ at $9000 \mathrm{r} / \mathrm{min}$. The supernatants collected were analyzed for the metal ion. All of these uncertain influence conditions were predetermined before respective adsorption experiments based on previous literature $[13,14]$. The amounts of the metal ion adsorbed by the adsorbents were calculated by dithizone spectrophotometry [15].

The sorption rate $(P \%)$ and amount of metal ion adsorbed by the bentonite adsorbents $(Q)$ were calculated as:

$$
\begin{gathered}
P \%=100\left(C_{o}-C_{e}\right) C_{\mathrm{o}} \\
Q=\frac{\left(C_{o}-C_{e}\right) V}{m}
\end{gathered}
$$

where $\mathrm{C}_{o}$ and $\mathrm{C}_{e}$ are the concentration of metal ion in the initial and equilibrium concentration of metal ion in solution $(\mathrm{mg} / \mathrm{L}), \quad V$ is the volume of metal ion solution used (mL) and $m$ is the weight of the adsorbent used (g).

\section{Results and Discussion}

\subsection{Effect of Contact Time}

A fixed particles size of the adsorbents reagent (through $200 \mathrm{mesh}$ ) was added to $100 \mathrm{~mL}$ of zinc ions solution which adjusted $p \mathrm{H}$ to 5 at concentration $0.005 \mathrm{~mol} / \mathrm{L}$, with liquid-to-solid ratio of $100 \mathrm{~mL} / \mathrm{g}$ at $20^{\circ} \mathrm{C}$. At different time an interval of 0-120 min, the adsorption rate of $\mathrm{Zn}^{2+}$ on the bentonite adsorbents has shown in Figure 1. As seen from the figure, there is a rapid uptake within the first $15 \mathrm{~min}$. Increasing contact time allows greater amounts of $\mathrm{Zn}^{2+}$ to be removed from the aqueous solution. 120 min later, the adsorption reached equilibrium.

Ünlü N. et al. [16] took kinetic considerations into account and found that the presence of functional groups 


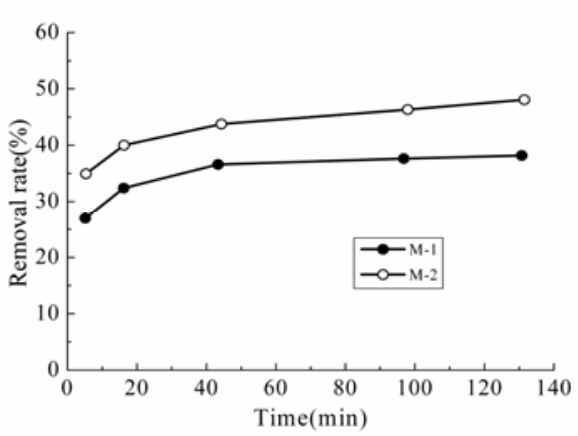

Figure 1. Effect of contact time on the adsorption of $\mathrm{Zn}^{2+}$ ions onto bentonite and Na-bentonite.

is greatly determined by porous structure of polymeric matrics. As was shown by $\mathrm{H}$ Woehlecke et al. [17], in our study the observed rapid uptake can be attributed to the porous structure of the bentonite adsorbents.

\subsection{Effect of Temperature}

In order to evaluate the effect of temperature on adsorption characteristics of the bentonites, the experiment was studied at a constant initial concentration of $5 \times 10^{-3}$ $\mathrm{mol} / \mathrm{L}$, bentonite particles size through 200 mesh, liquid-to-solid ratio of $100 \mathrm{~mL} / \mathrm{g}$ and $\mathrm{pH} 5$ at stirring speed of $1200 \mathrm{r} / \mathrm{min}$, adsorption time $120 \mathrm{~min}$. The results of the studies on the influence of temperature on cation adsorption are presented in Figure 2 in terms of amount of metal removed versus temperature. It can be seen that the percentage zinc uptake on both M-1 and M-2 increases with increasing temperature. The reason for this is that as the temperature increases, the ionic velocity accelerates. The ion exchange reaction was hastened.

In earlier publication, the effect of temperature on adsorption is important not only because it affects the rate and extent of adsorption but also due to the fact that temperature dependence of adsorption provides informa tion about possible adsorbate-adsorbent interaction [1820].

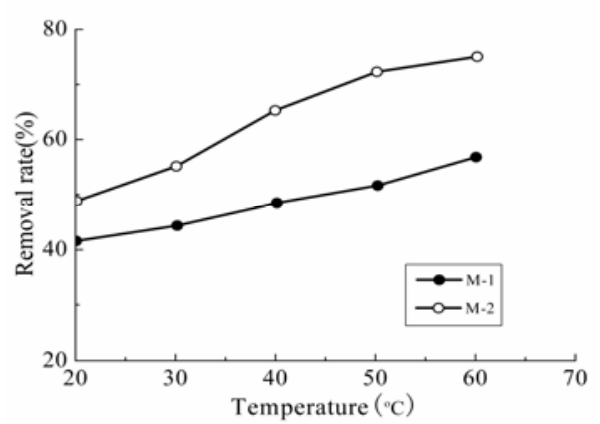

Figure 2. Effect of solution temperature on the adsorption of $\mathrm{Zn}^{2+}$ ions onto bentonite and Na-bentonite.

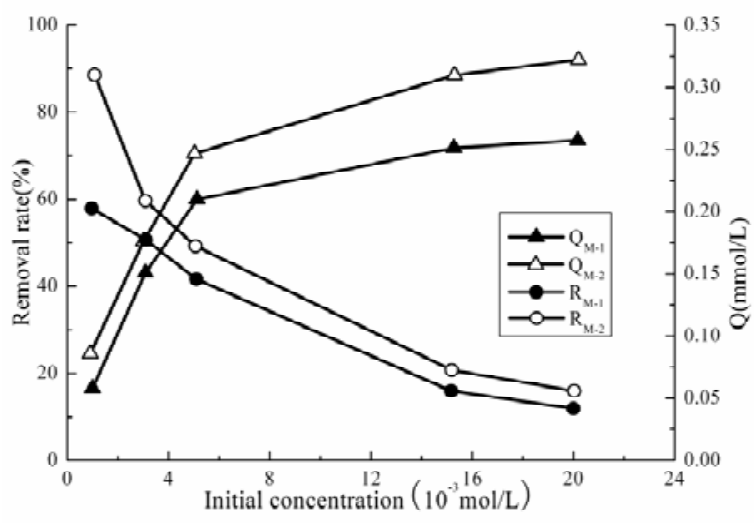

Figure 3. Relationship between initial metal ion concentration and $\mathrm{Zn}^{2+}$ adsorption.

\subsection{Effect of Initial Concentration}

The effect of initial concentration was investigated under the following conditions: the bentonite particles size (through $200 \mathrm{mesh})$, liquid-to-solid ratio $(100 \mathrm{~mL} / \mathrm{g}), \mathrm{pH}$ (through $200 \mathrm{mesh})$, liquid-to-solid ratio $(100 \mathrm{~mL} / \mathrm{g}), \mathrm{pH}$ (5), temperature $\left(20^{\circ} \mathrm{C}\right)$, stirring speed $(1200 \mathrm{r} / \mathrm{min})$, adsorption time (120 min). Figure 3 has shown the adsorption of zinc ions onto M-1 and M-2 samples. The amount of metal ion adsorbed increased gradually with different initial concentration varying from 0 to $0.02 \mathrm{~mol} / \mathrm{L}$. However, the adsorption rate decreased with increasing initial metal ion concentration.

The adsorption mechanism of $\mathrm{Zn}^{2+}$ by bentonite in zinc chloride solution is:

$$
\mathrm{Zn}^{2+}+\mathrm{M}-\text { Mont }=\mathrm{Zn}-\text { Mont }+2 \mathrm{M}
$$

where $\mathrm{M}$ is the cation in montmorillonite interlayer, $\mathrm{M}$ Mont and $\mathrm{Zn}$-Mont are M-montmorillonite and zincmontmorillonite.

With other conditions unchanged, the increase of $\mathrm{Zn}^{2+}$ concentration controls the direction of adsorption reactions for positive reaction. The amount of zinc ion adsorbed increased. On the other hand, the higher concentration of $\mathrm{Zn}^{2+}$ is, the more $\mathrm{Zn}^{2+}$ remained after equilibrium. For this reason, the percentage of zinc ion adsorbed decreased with increasing initial concentration.

\subsection{Effect of Liquid-to-Solid Ratio}

In condition of initial concentration is $5 \times 10^{-3} \mathrm{~mol} / \mathrm{L}$, bentonite particles size through 200 mesh, $\mathrm{pH}$ 5 , temperature of $20^{\circ} \mathrm{C}$, stirring speed of $1200 \mathrm{r} / \mathrm{min}$, contact time $120 \mathrm{~min}$. The amount of zinc adsorbed reduced with increasing liquid-to-solid ratio as shown in Figure 4. It indicates that the adsorption capacity of M-1 and M-2 improved with the increase of bentonite dosage.

In terms of Equation (3), the increase of bentonite dosage (that is liquid-to-solid ratio reduced) is propitious 


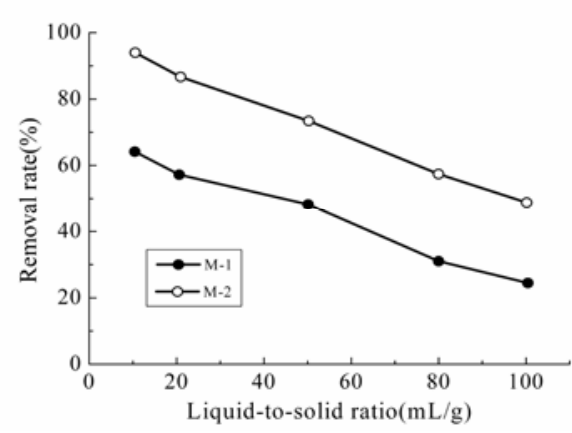

Figure 4. Effect of liquid-to-solid ratio on the adsorption of $\mathrm{Zn}^{2+}$ ions onto bentonite and Na-bentonite.

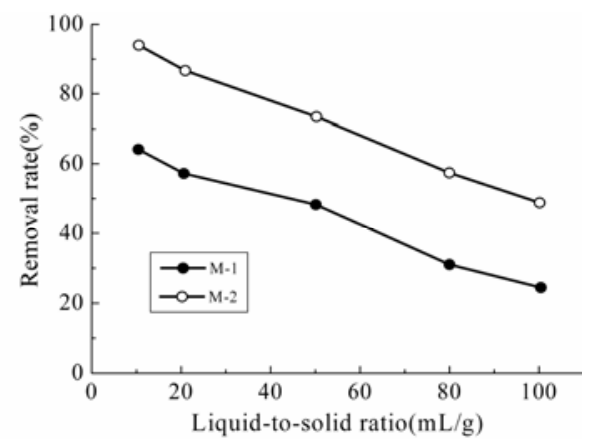

Figure 5. Effect of $\mathrm{pH}$ on the adsorption of $\mathrm{Zn}^{2+}$ ions onto bentonite and Na-bentonite.

to positive reaction with other conditions unchanged. As a result, the concentration of $\mathrm{Zn}^{2+}$ remained after equilibrium declined, register as a raise in percentage of metal ion adsorbed.

\subsection{Effect of PH}

To determine the $\mathrm{pH}$ necessary for adsorption, liquidto-solid ratio is $100 \mathrm{~mL} / \mathrm{g}$ of solution containing 0.005 $\mathrm{mol} / \mathrm{L}$ metal ion and particles size through 200 mesh were stirred at $1200 \mathrm{r} / \mathrm{min}$ at varying time intervals $(0$ $120 \mathrm{~min})$ at $20^{\circ} \mathrm{C}$. Figure 5 indicates that the adsorption capacity of M-1 and M-2 was dependent on $\mathrm{pH}$.

In general, the adsorption of ion on clay mineral includes exchange adsorption and specific adsorption. The exchange adsorption is of $\mathrm{pH}$-independent constant, which has relation to permanent charge of clay mineral [21]. Therefore, it can be seen that the $\mathrm{pH}$-dependent percentage of zinc ion adsorbed belongs to reinforcement of specific adsorption.

\subsection{Effect of Stirring Speed}

The impact studies of stirring speed on zinc ion uptake capacities under the following conditions: initial concentration is $5 \times 10^{-3} \mathrm{~mol} / \mathrm{L}$, bentonite particles size through 200 mesh, $\mathrm{pH}$ is 5 , temperature of $20^{\circ} \mathrm{C}$ and adsorption

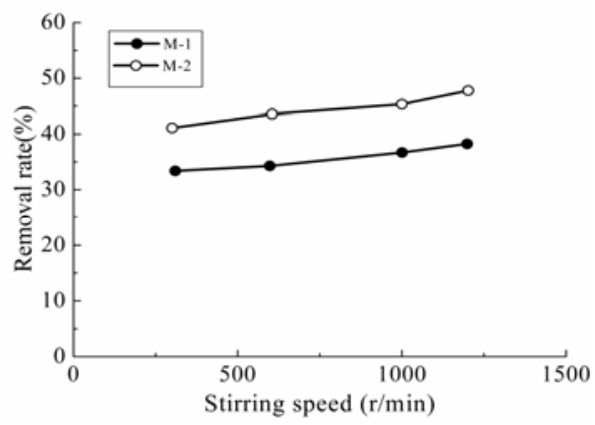

Figure 6. Effect of stirring speed on the adsorption of $\mathbf{Z n}^{2+}$ ions onto bentonite and Na-bentonite.

time is $120 \mathrm{~min}$. As shown in Figure 6, we can get the effect of stirring speed.

Experimental data is processed to obtain regression equation of stirring speed and adsorption rate respectively:

$$
\begin{gathered}
W_{M-1}=1.78 v+31.25, \quad R_{M-1}=0.9957 \\
W_{M-2}=2.2331 v+39.003, \quad R_{M-2}=0.9994
\end{gathered}
$$

where $W_{M-1}$ and $W_{M-2}$ are adsorption rate of M-1and $\mathrm{M}-2, v$ is stirring speed.

From above equations and Figure 6, we can draw the conclusion that adsorption rate of bentonite are increased by stirring speed and they are linear correlation. The reason is that with other conditions unchanged, accelerate stirring speed makes the velocity of $\mathrm{Zn}^{2+}$ increased and then facilitates adsorption. Furthermore, a higher stirring speed would be propitious to bentonite dispersion, increase BET of bentonite and enhance bentonite adsorption.

\subsection{Effect of Particle Size}

Figure 7 shows the removal efficiencies for different particle sizes under the conditions of the initial concentration $5 \times 10^{-3} \mathrm{~mol} / \mathrm{L}$, liquid-to-solid ratio $100 \mathrm{~mL} / \mathrm{g}$, $20^{\circ} \mathrm{C}$, pH 5 , stirring speed of $1200 \mathrm{r} / \mathrm{min}$, adsorption time $120 \mathrm{~min}$. As can be seen from the graph, the smaller particle size is, the higher adsorption rate is. This may be in connection with crystal morphology and surface properties of montmorillonite. The crystal of montmorillonite overlapped in lamellar-type. Binding force between the crystal face is weaker, this led to peeling along the layer easily. When particle size becomes smaller, radiusthickness ratio would largen and the BET double increase. The electroactive of grain cross-section simultaneously enhances, resulting in the removal rate of $\mathrm{Zn}^{2+}$ by bentonite improved obviously [19].

\subsection{Effect of the coexisting ions}

In order to investigate the respective effect of the $\mathrm{Pb}^{2+}$ and $\mathrm{Cr}^{6+}$ presence in the aqueous solution on the sorption 


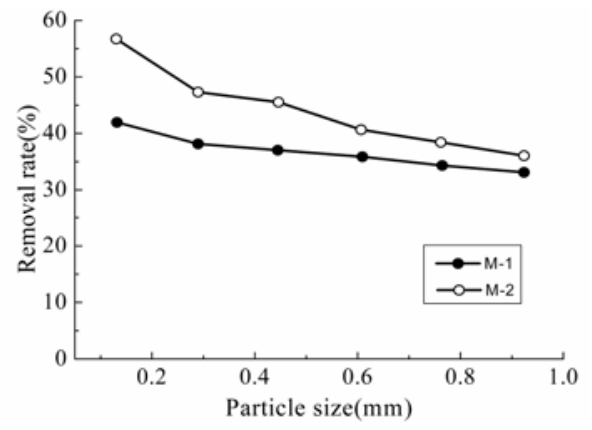

Figure 7. Effect of particle size on the adsorption of $\mathrm{Zn}^{2+}$ ions onto bentonite and Na-bentonite.

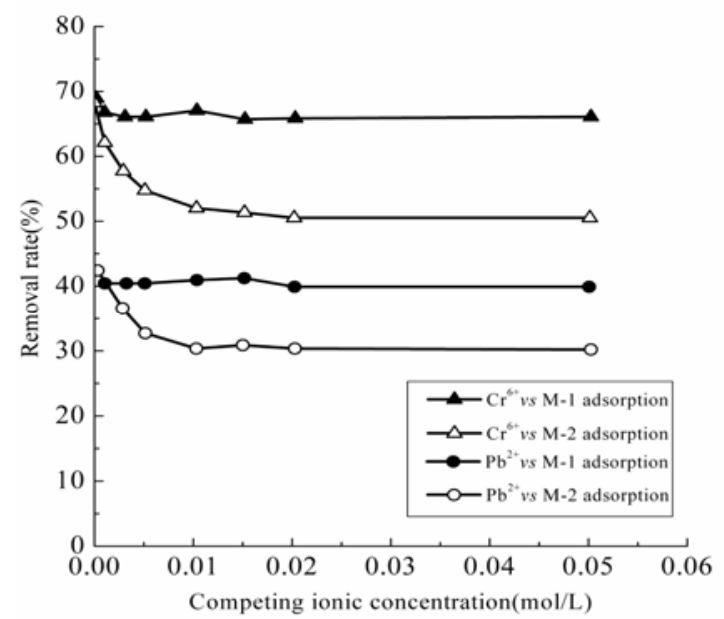

Figure 8. Effect of competing ionic concentration on the adsorption of $\mathrm{Zn}^{2+}$ ions onto bentonite and Na-bentonite.

of $\mathrm{Zn}^{2+}$ onto the bentonite adsorbents, we prepared various amounts of $\mathrm{Pb}^{2+}$ and $\mathrm{Cr}^{6+}$ solutions with maintaining all other conditions as above. The results, shown in Figure 8, clearly indicate that the simultaneous presence of $\mathrm{Cr}^{6+}$ and $\mathrm{Zn}^{2+}$ in aqueous solutions reduced the equilibrium adsorption capacity of bentonite adsorbents, while there was hardly effect in the simultaneous aqueous solution of $\mathrm{Pb}^{2+}$ and $\mathrm{Zn}^{2+}$.

This may be attributed to the ionic radius, hydrated radii and valence of the ions [22]. The higher the electro valence is, the smaller is the ion radius with easier interchanges reaction. $\mathrm{Cr}^{6+}$ is of the greatest electro valence, the least hydrated radii and the strongest competitiveness among $\mathrm{Cr}^{6+}, \mathrm{Pb}^{2+}$ and $\mathrm{Zn}^{2+}$.

Accordingly, $\mathrm{Cr}^{6+}$ displaces zinc cation, resulting in a decline of percentage of zinc ion. $\mathrm{Pb}^{2+}$ is of larger hydrated radii than $\mathrm{Zn}^{2+}$. Similarly, $\mathrm{Pb}^{2+}$ could not displace zinc cation, resulting in no effect on adsorption of $\mathrm{Zn}^{2+}$.

\subsection{Adsorption isotherm}

The adsorption behavior of M-1 and M-2 samples was

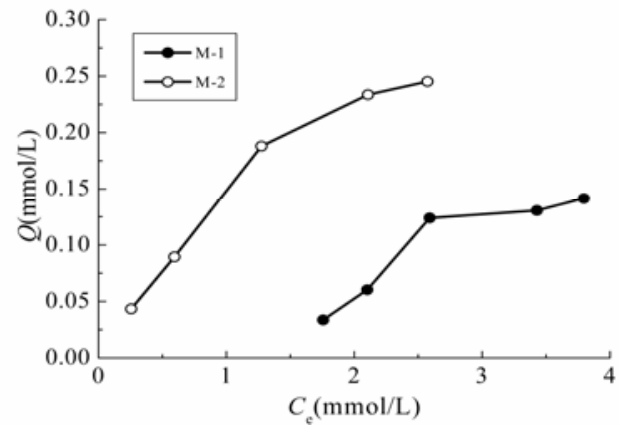

Figure 9. Adsorption isotherm of $\mathrm{Zn}^{2+}$ ions onto bentonite and Na-bentonite.

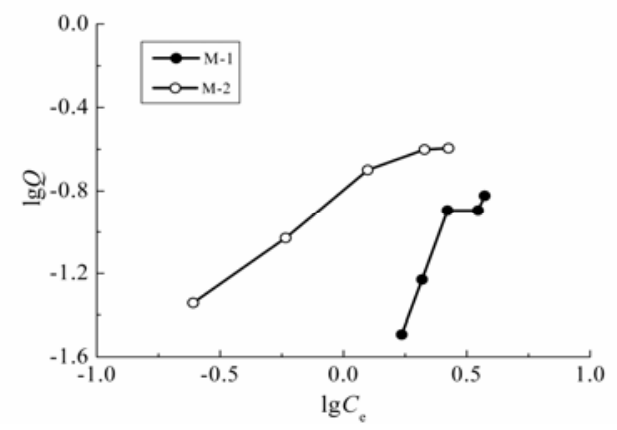

Figure 10. Relationship between $\lg Q$ and $\lg C_{\mathrm{e}}$.

studied and the results obtained depicted in Figure 9. As shown in Figure 10, the plot of $(\lg Q)$ versus $\left(\lg \mathrm{C}_{\mathrm{e}}\right)$ for adsorption of $\mathrm{Zn}^{2+}$ onto bentonites can be seen.

In this study, linear coefficients of determination test were used. Linearised forms of the two curves were:

$$
\begin{aligned}
& \lg Q_{\mathrm{M}-1}=1.8671 \lg \mathrm{C}_{\mathrm{e}, \mathrm{M}-1}-1.849, \mathrm{R}_{\mathrm{M}-1}=0.9278 \\
& \lg Q_{\mathrm{M}-2}=0.78291 \mathrm{gC}_{\mathrm{e}, \mathrm{M}-2}-0.8811, \mathrm{R}_{\mathrm{M}-2}=0.99
\end{aligned}
$$

As is seen from above, both (6) and (7) are found to fit the linearised form of Freundlich equation [23]:

$$
\lg \mathrm{q}_{\mathrm{e}}=\lg K_{F}+1 / n \lg \mathrm{C}_{\mathrm{e}}
$$

where $\mathrm{q}_{e}$ is the amount of solute adsorbed per unit weight of adsorbent ( $\mathrm{mg} / \mathrm{g}), \mathrm{C}_{\mathrm{e}}$ the equilibrium concentration of solute in the bulk solution $(\mathrm{mg} / \mathrm{l}), K_{F}$ the constant indicative of the relative adsorption capacity of the adsorbent $(\mathrm{mg} / \mathrm{g})$ and $1 / n$ the constant indicative of the intensity of the adsorption. We can conclude that adsorption isotherms of bentonites for zinc ion could be expressed mathematically in terms of Freundlich models. Rearranged these equations, we obtain:

$$
\begin{aligned}
& Q_{M-1}=0.0142 \mathrm{C}_{\mathrm{e}, \mathrm{M}-1}^{0.5356} \\
& Q_{M-2}=0.1315 \mathrm{C}_{\mathrm{e}, \mathrm{M}-2}^{1.2773}
\end{aligned}
$$

\section{Conclusions}

Local bentonite and its Na-modified form were tested as 
adsorbent material for the removal of zinc ions from waste solutions. The results indicate that removal of $\mathrm{Zn}^{2+}$ by Na-exchanged bentonite is more effective than by Ca-bentonite. Compared to the published data in the same field, it is found to be in agreement with most of them.

The adsorption experiments were conducted under different conditions. The extent of zinc adsorption increased with increase in $\mathrm{pH}$, temperature, stirring speed, contact time and decrease in particle size, initial concentration, liquid-to-solid ratio.

In a complex system, the simultaneous presence of $\mathrm{Cr}^{6+}$ and $\mathrm{Zn}^{2+}$ in aqueous solutions reduced the equilibrium adsorption capacity of bentonite adsorbents, while there was no effect in the simultaneous aqueous solution of $\mathrm{Pb}^{2+}$ and $\mathrm{Zn}^{2+}$.

The adsorption of $\mathrm{Zn}^{2+}$ ions onto bentonite and Naexchanged bentonite can be expressed with Freundlich type sorption isotherms.

\section{Acknowledgements}

This research was financially supported by National Natural Science Foundation of China (Grant No.41072 031, 41072119) and Natural Science Foundation of Hebei Province (Grant No. D2009000833).

\section{REFERENCES}

[1] C. G. Fraga, "Essentiality and Toxicity of Trace Elements in Human Health," Molecular Aspects of Medicine, 2005, Vol. 26, pp. 235-244.doi:10.1016/j.mam.2005.07.013

[2] Y. H. Liu, X. B. Wan, A. H. Li and Y. Y. Dong, "Bentonite Modified and Its Purification of $\mathrm{Zn}^{2+}$ in Water," Chemistry and Bioengineering, 2007, Vol. 24, No. 3, pp. 34-35.

[3] Z. A. Wang, Y. M. Zhu, D. Z. Wei and S. J. Dai, "Research on Adsorption of $\mathrm{Zn}^{2+}$ from Wastewater by Ca-Bentonite," Non-ferrous Mining and Metallurgy, Vol. 22, No. 2, 2006, pp. 45-47.

[4] J. F. Pan and J. Lu, "Experimental Study on Adsorbing the $\mathrm{Pb}^{2+} 、 \mathrm{Ni}^{2+} 、 \mathrm{Cd}^{2+}$ from Wastewater with Natural Ca-Bentonite and Modified Ca-Bentonite," China Mining Magazine, Vol. 9, 2008, pp. 35-138.

[5] J. F. Hodgson, "Cobalt Reactions with Montmorillonite," Soil Science Society of America Proceedings, Vol. 24, 1960, pp. 165-168.

[6] P. Peigneur, A. Maes and A. Cremers, "Heterogeneity of Charge Density Distribution in Montmorillonite as Inferred from Cobalt Adsorption," Clays and Clay minerals, Vol. 23, 1975, pp. 71-75.

doi:10.1346/CCMN.1975.0230110

[7] M. F. Brigatti, F. Corradini, et al., "Interaction between Montmorillonite and Pollutants from Industrial WasteWater: Exchange of $\mathrm{Zn}^{2+}$ and $\mathrm{Pb}^{2+}$ from Aqueous Solutions," Applied Clay Science, Vol. 9, 1995, pp. 383-385.

\section{doi:10.1016/0169-1317(94)00027-N}

[8] M. J. Garcia and A. L. Page, "Influence of Ionic Strength and in Organic Complex Formation on the Sorption of Trace Amounts of Cd by Montmorillonite," Soil Science Society of America Proceedings, Vol. 40, 1976, pp. 658-663.

[9] H. Omar, H. Arida and A. Daifullan, "Adsorption of ${ }^{60} \mathrm{Co}$ Radionuclides from Aqueous Solution by Raw and Modified Bentonite," Applied Clay Science, Vol. 44, 2009, pp 21-26. doi:10.1016/j.clay.2008.12.013

[10] S. T. Akar, T. Akar and Z. Kaynak, "Removal of Copper (ii) Ions from Synthetic Solution and Real Wastewater by the Combined Action of Dried Trametes Versicolor Cells and Montmorillonite," Hydrometallurgy, Vol. 97, 2009, pp. 98-104. doi:10.1016/j.hydromet.2009.01.009

[11] E. Alvarez-Ayuso and A. Ganchez-Sanchez, "Removal of Heavy Metals from Waste Waters by Natural and Na-exchanged bentonite." Clays and Clay Minerals, Vol. 51, No. 5, 2003, pp. 475-480.

doi:10.1346/CCMN.2003.0510501

[12] W. Matthes, F. T. Madsen and G. Kahr, "Sorption of Heavy-Metal Cations by Al and Zr-hydroxy Intercalated and Pillared Bentonite," Clays and Clay Minerals, Vol. 47, No. 5, 1999, pp. 617-629. doi:10.1346/CCMN.1999.0470508

[13] G. Bayramoglu and M. Y. Arica, "Construction a Hybrid Biosorbent Using Scenedesmus Quadricauda and Ca-Alginate for Biosorption of $\mathrm{Cu}$ (II), $\mathrm{Zn}$ (II) and $\mathrm{Ni}$ (II): Kinetics and Equilibrium Studies," Bioresource Technology, Vol. 100, 2009, pp. 186-193. doi:10.1016/j.biortech.2008.05.050

[14] E. Eren, "Removal of Copper Ions by Modified Unye clay, Turkey," Journal of Hazardous Materials, Vol. 159, 2008, pp. 235-244. doi:10.1016/j.jhazmat.2008.02.035

[15] Ministry of Environmental Protection of the People's Republic of China, Committee on Water and Wastewater Monitoring Methods, "Monitoring Analysis Method of Water and Wastewater," Environmental Science Press of China, Beijing, 2002.

[16] N. Ünlü and M. Ersoz, "Removal of Heavy Metal Ions by Using Dithiocarbamated-Sporopollenin," Separation and Purification Technology, Vol. 52, 2007, pp. 461-469. doi:10.1016/j.seppur.2006.05.026

[17] D. Hunkeler and L. R. Ehwald, "Cell Physiology and Interactions of Biomaterials and Matrices," Proceedings of the X International BRG Workshop on Bioencapsulation, 2002, pp. 183-186.

[18] M. Alkan, B. Kalay, M. Doğan and Ö. Demirbaş, "Removal of Copper Ions from Aqueous Solutions by Kaolinite and Batch Design," Journal of Hazardous Materials, Vol. 153, 2008, pp. 867-876. doi:10.1016/j.jhazmat.2007.09.047

[19] S. L. Ding and C. G. Sun, "Study on Factors Affecting Adsorption of $\mathrm{Cr}^{6+}$ in Wastewater by Bentonite," Non-metallic Mines, Vol. 29, No. 3, 2006, pp. 45-48.

[20] E. I. Unuabonah, B. I. Olu-Owolabi, K. O. Adebowale, et al. "Adsorption of Lead and Cadmium Ions from Aque- 
ous Solutions by Tripolyphosphate-Impregnated Kaolinite Clay," Colloids and Surfaces A: Physicochemical and Engineering Aspects, 2007, Vol. 292, pp. 202-211. doi:10.1016/i.colsurfa.2006.06.024

[21] H. P. He, "Study on the Effect of Metal Ions and Clay Mineral," Petroleum Industry Press, Beijing, 2001.

[22] P. X. Wu, "Clay Mineral Materials and Environmental
Remediation," Chemical Industry Press, Beijing, 2004.

[23] S. L. Ding, Y. Z. Sun, C. N. Yang and B. h. Xu, "Removal of Copper from Aqueous Solutions by Bentonites and the Factors Affecting it," Mining Science and Technology, 2009, Vol. 19, No. 4, pp. 489-492. doi:10.1016/S1674-5264(09)60091-0 